\title{
Culture and Leadership in the 21st Century
}

\author{
Remi Alapo \\ University of Phoenix, Arizona, USA
}

\begin{abstract}
Some factors that have contributed to the need for organizational leaders to adapt, and adjust to other national cultures are the globalization of the workforce, the expansion of international companies, and exposure of many national organizations to increased business competition. The increased competition has forced organizational leaders to engage in the understanding of the cultural limitations of organizations and their leadership practices. In addition, cross-cultural leadership researchers in 21st century are cognizant of the fact that culture is a condition, and a boundary to previous leadership theories and practices. Using Gerte Hofstede's cultural dimension model, culture and organizational leadership as they relate to the leadership practices of participants, and National and Family Cultures are examined in this revised paper. ${ }^{1}$
\end{abstract}

Keywords: Hofstede’s cross, cultural leadership, power distance, culture and leadership, national culture, family culture, cross-cultural leadership, culture and leadership styles

\section{Introduction}

The 21st century has been met with increases in integrating cultures and economies on a faster pace (Suk-Hing Chan, 2005). There is a demand in the global economy for national cultures to adjust and adapt to global market trends. From this wide-scale of multi-national business practices in cross-cultural environments, both national and organizational leaders can step outside of their country's norms as new national cultures and leadership practices emerge. As the world integrates businesses and cultures, many organizational leaders are crossed between their cultural beliefs, norms, practices, and leadership approaches in the ways in which they understand cultural influences on leadership (Hanges, Lord, \& Dickson, 2000).

Some factors that have contributed to the need for organizational leaders to adapt, and adjust to other national cultures are the globalization of the workforce, the expansion of international companies, and exposure of many national organizations to increased business competition. The increased competition has forced organizational leaders to engage in understanding of the cultural limitations of organizations and their leadership practices. In addition, cross-cultural leadership researchers in the 21st century are cognizant of the fact that culture is a condition, and a boundary to previous leadership theories and practices (Hanges, Lord, \& Dickson, 2000).

Two studies reflected opposing views on the nature of a person's cultural influence on his or her leadership style. The underlying argument in these studies is that in organizations, the environmental factors present in the society affects the leadership practices of leaders. An appropriate leadership style or practice in

\footnotetext{
Remi Alapo, Doctor of Management (D.M), Organizational Management and Leadership, University of Phoenix.

1 The following is a revised section on culture and leadership, a part of the dissertation research by Alapo, R. (2011). The Role of Culture on the Leadership Styles of Women in Nigeria: A phenomenological Study.
} 
one culture may not be appropriate in another (Hanges, Lord, \& Dickson, 2000). Globalization has moved leaders towards common goals, such as being effective and remaining competitive in an innovative 21st century. The national culture of a person's country may be different from the leadership practice of another, therefore it is an ambiguous statement to previous cross-cultural leadership theories that a universal leadership practice exists. That is why it is important for organizational leaders to learn about and adapt to cross-cultural leadership practices and leadership styles of environments in which they work or one where they conduct business (Okpara, 2007).

\section{National Culture}

In a study on national culture and leadership, proponents of culture-specific perspective maintain that the effectiveness of leadership is unique and depends on national culture (Zagoršek, 2004). These authors argue that a person's beliefs, values, ideals, and norms are deeply rooted in a person's leadership practices, and that national culture affects the leadership behaviors, styles, goals, structure, culture, and strategies of organizations. Central to organizing a core belief to understanding a person's leadership style is national culture (Newman, 2003).

National culture implies that an acceptable way or practice of leadership in one culture may not be preferred in another. Social psychologists have argued that culture is socialized in a person through shared values of social groups that play key roles in a person's cognitive, emotional, and social functioning. These socialization patterns, in turn, shape how people perceive the self and others in cross-cultural environments (Markus \& Kitayama, 1991; Triandis, 1989).

\section{Family Culture}

Cultural factors affect leadership in many ways. Leaders, especially within the extended family system see themselves as working for members of the family as well as for the extended family, rather than for his or her own immediate gratification. In culturally inclusive societies, organizational leaders view themselves based on their family name, responsibilities, and the societal construct of how a man or woman should or should not behave amongst peers, subordinates, and others in the work environment. Societal constructs are based on age, gender, level of education, and region. Decision-making in many family culture relies on patrilineal family and social structures, in which individuals foremost will base their leadership style on the national and family culture of their societies. Therefore, national culture affects personality, attitudes, and behaviors of a leader or person in positions of power (Ejiofor, 1987; Okpara, 1996).

Previous studies relating cross-cultural leadership issues to work behaviors, have concluded that cultural factors influence a person's leadership style (Ejiofor, 1987; Okpara, 1996). Universalities and culture-specificities are more likely to be found than not, in places or societies where family culture and tradition are very strong. Previous studies confirmed the notion that perceptions of what makes an effective and ineffective leader are similar in content across cultures. With variations of what is important, especially between similar cultures that share an overarching value structure, such as religion. There are large variations on how people perceive leadership in cultures different from each other (Dastmalchian, Javidan, \& Alam, 2001; Ling, Chia, \& Fang, 2000).

\section{Culture and Leadership Styles}

From a social perspective, culture is defined as a collective understanding of different people who 
distinguish themselves as a group having different practices, beliefs, values, and norms from the other (Hofstede, 1980; Rodriguez, 1996). Leaders that learn to adapt to and interact with others in another culture are more likely to develop a successful, long-term business relationship because they have expanded their cultural understanding of another person or country's national culture. Leaders that do not have a clear understanding of the national culture present in their environments when they are leading in the 21st century can have failures in their leadership even when they have good organizational strategy in place. Culture is the set of ideas, attitudes, behaviors, and values common to a group of people. Culture shapes the human behavior that is different from one society to another. The attitudes, behaviors, and values mentioned above take on added meaning with respect to time, language, and cultural context. This definition is consistent with other definitions that national culture defines on behaviors, attitudes, and values of the members of that society (Hunt, Osborn, \& Shermerhorn, 1994; Newman \& Nollen, 1996).

\section{Hofstede’s Cross-cultural Framework}

Culture is the collective programming of the mind that distinguishes the members of a group from another (Hofstede, 1980). Hofstede’s work highlights differences in Western and Eastern cultures and is most widely cited in cultural studies (David, 2007). Another definition of culture is as follows:

Culture consists in patterned ways of thinking, believing and reacting, acquired and transmitted mainly by symbols, constituting the distinctive achievement of human groups, including their embodiments in artifacts; the essential core of culture consists of traditional (e.g., historically derived and selected) ideas and especially their attached values. (Unger, Papastamatelou, Gassemi, \& Lu, 2014)

A cultural dimension model based on a research study done in 67 countries was developed from a study, where influences of culture on individual behavior were in observation. In these studies, five cultural dimensions which can address changes of culture and management in a society were observed: power distance, individualism versus collectivism, masculinity versus femininity, and long-term versus short-term orientation and they were named GerteHofstede’s five dimensions of culture (Hofstede, 1980, 1991, 1994, and 2001).

\section{Power Distance}

Describes the degree of inequality amongst people considered acceptable in a society. Power distance is the extent to which a society accepts that power distributes unequally, and measures the degree to which there is a psychological distance between a leader and his or her followers. Power distance is a continuum, with small power distance on the left and large power distance on the right. Leaders with small power distances prefer the democratic approach to sharing power with everyone in the group. Leaders with high power distance tend to be autocratic with power centralized in the hands of a few, such as with the elite, often based on class differentiation. This dimension refers to the comfort level that people have in interaction and decision-making decisions within the hierarchical structure of the organization. High power distance is present when subordinates do not feel good about decisions made by leaders. Low power distance indicates that subordinates may wonder why leaders have a slow pace to decision-making. Power distance also refers to the perceptual inequality among people between different cultures. Societies that have high power distance tend to have a highly centralized management system (Zhang, 1994; Hofstede, 1994; Randolph \& Sashkin, 2002).

\section{Individualism and Collectivism}

Individualism is the notion that an individual is the primary unit of reality, giving it ultimate value. In 
contrast to collectivism, which maintains that the group holds the ultimate value, and stresses the needs for individuals as subordinate to those of the group. An individual's welfare is an end goal and should not sacrifice any individual for the sake of another. Collectivists look at reality as mediation among the group and consequently, give the group the authority to confront reality rather than the individual. This collectivist view can be said as true for cultures where there is huge national and family culture presence in the leadership practices of leaders (Stata, 1992).

Individualism starts from the premise that to get to know the whole, it is necessary and sufficient to know the elementary or 56 atomic facts. It adopts the norm to tackle problems one at a time. Epistemological individualism focuses on the individual knower isolated from the learning community. It is true that cognition is a brain process, but individuals do learn from interaction with other group members (Bunge, 2000). Individualism as a priority to personal goals over those of the group, while he referred to collectivism as the concept of giving priority to the group over the individual. This dimension describes the level to which individualism and collectivism depend on the values of the society as well as other factors such as educational levels and subcultures within the organization (Lee, 1992).

\section{Masculine and Feminism}

This dimension describes the degree to which society perceive values and traits that are associated with masculine qualities. Masculine imagery is deprived of sensitivity towards themselves and others with the attainment of social status and material wealth; masculine males are expected to be independent and display assertiveness. In contrast, qualities of femininity include nurturing and sympathy. This dimension also describes the difference between genders as well as the characteristics of one gender prevailing over the other (Hofstede, 1994, 2001). Masculinity refers to the degree that certain values such as assertiveness, performance, and competitiveness prevail over feminine values such as quality of life, warm personal relationships, service, and solidarity. Dimensions of masculinity are preferred in societies where males are favored in leadership positions, certain professions are attributed to masculine pride and preferably chosen for male members of the family rather than for females. This aspect also holds true that the national culture in many societies is patriarchal. This duality of concepts interprets differently in various cultures however (Hofstede, 1994; Rodriguez, 1996).

\section{Uncertainty Avoidance}

This dimension describes the extent to which a person candeal with threatening, ambiguous, or anxiety-provoking situations. Strong uncertainty avoidance associates with traditional cultures while weak uncertainty avoidance associates with contemporary cultures. This dimension describes the amount of uncertainty that can coexist with the amount of tolerance people can have for uncertain situations (Hofstede, 1994, 2001). A high-level of uncertainty avoidance indicates that subordinates prefer carefully detailed goals, assignments, policies, and procedures. In low levels of uncertainty avoidance, subordinates can tolerate unclear descriptions of the goals, processes, and procedures. A low-level of uncertainty avoidance can lead to chaos if presented in an environment in which subordinates prefer clarity. Organizations with high uncertainty avoidance culture adhere to the organizational hierarchy in management, processes, rules, and regulations (Zhang, 1994; Randolph \& Sashkin, 2002).

\section{Long-term and Short-term Orientation}

This is the last dimension which refers to the degree to which organizations adopt either long or short-term 
performance strategies (Hofstede, 2001; Hunt et al., 1991). This cultural dimension derived from research done by Michael Bond using the Chinese values survey in support of Confucian dynamism and focusing on relationships, thrift, a sense of shame, personal steadiness, reciprocity, and respect for tradition (Hunt et al., 1991). Long-term orientation reflects persistence, perseverance, and thrift as compared to short-term orientation that reflects personal stability, respect, tradition, and fulfilling social expectations. Hofstede stated that long-term orientation stands for the fostering of virtues, rewards, perseverance, and thrift. Its opposite pole, short-term orientation, which stands for the fostering of virtues related to the past and present, in particular, a respect for tradition, preservation, and fulfilling social obligations (Hoppe, 1990).

An important insight into the validity of data that may not be universal of socio-cultural dimensions relevant to leadership, as in the case of their discoveries on studies of leadership between the East (countries of the former Soviet Union), and the West (the United States and Germany) (Ardichvili \& Kuchinke, 2002). Grouping countries based on cultural, geographic, or religious proximity could be equally questionable. For example, one may expect that Thailand, Cambodia, and Laos would form a homogeneous subset because of proximity and sharing of similar religious beliefs. These countries are quite different (Mom-Chhing, 2009). Regional differences within countries may also influence leadership style from one country to the other.

Another example, one may expect that Nigeria has the same culture throughout the country but the national culture is different from the family culture or other traditional practices that vary from each Nigerian society or community to the other. Therefore, leadership and management development recommendations based on country profiles, and grounded in Hofstede's dimensions should be conducted with caution to ensure their validity. Hofstede's work provides practical applications in cross-cultural training and development to help people work more effectively in more than one culture. Application of dimensions can help people understand their own cultural tendencies (Rosenhauer, 2007).

\section{Problem}

The universal 21st century global market leadership culture is in direct conflict with the national and family cultures of Nigeria.

\section{Purpose}

The purpose of this section of the research was to investigate Nigerian women in leadership positions and the relationship of both national and family cultures as they relate to their leadership practices. This section ${ }^{2}$ of the research study provides the descriptive analysis on power and organizational leadership as they relate to both National and Family Cultures and to understand the effects of both national and family culture on power relations within the participant's respective places of business or organizations. The questions for this section were asked to understand the perspectives of research participants as they interpret their perceptions and the ways in which both national and family culture affected their leadership characteristics.

\section{Methodology}

The research group involved an organization, body of members, characterized by a unique culture, values,

\footnotetext{
2 These results are the descriptive analysis which have been revised and were based on the section on Culture and Leadership in the 21st Century. A dissertation research conducted by Alapo, R. (2011) titled: The Role of Culture on the Leadership Styles of Women in Nigeria: A Phenomenological Study.
} 
and social beliefs. The scope of this section of the research study was a practical orientation to examine applied power as used by individuals. A phenomenological qualitative research study explored the culture and leadership in a cross-cultural environment, examining both national and family cultures as the basis for cross-cultural leadership, and utilizing Gerte Hofstede's five cultural dimensions of culture as analysis for this section of the research on culture and leadership. The research was conducted amongst a group of 50 women, ages 35 to 50 years of age who were in leadership positions in an organization working to increase the number of women in management and leadership positions in Nigeria. An open-ended survey questionnaire was appropriate for the proposed research study because it allowed participants to describe their day-to-day lived experiences. The researcher gathered insights into the lived experiences of a like-minded sample of respondents from the research population as they described their cross-cultural leadership experiences. The following are the descriptive analysis of the section on power and organizational leadership.

\section{Results}

\section{Descriptive summary1: Role of National and Family Culture on power}

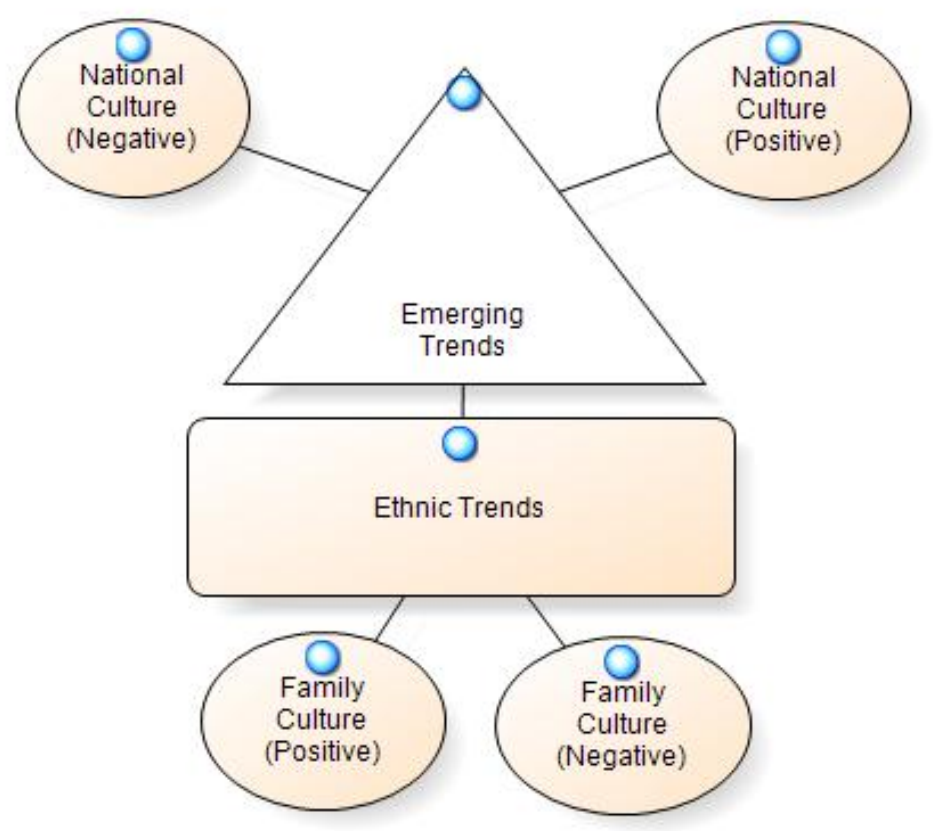

Figure 1. Emerging trends of national and family culture.

When asked to describe what the role of both the national and family culture of Nigeria was on the leadership styles of women, many of the participants responded both positively and negatively to this question. One respondent answered that national and family culture was an emerging trend because many people still expected women to submit to men, even when those women were more qualified. Another answered that the natural tendency of Nigeria's culture is to assign family roles to women. This culture is weakening as more and more women continue to succeed in the corporate, political and business worlds. Many of the respondents believed that "contrary to the common opinion that culture did not permit women to be leaders, culture, both family and national is viewed as a tool that helped to nurture the great potentials in women". 
For instance, culture lays emphasis on the woman as a home maker and by experience, the better home makers are better leaders. The national and family cultures in Nigeria are rapidly changing and now one can find more women in management and leadership roles. Especially since Nigeria returned to democratic rule in 1999, where more women are now involved in business and political leadership, and have been elected or appointed to serve in government, and lead major corporations in the country. "Their successes have marked a dynamic and transitional shift to climb to the economic and leadership ladder”.

From some participants' point of view, cultural perceptions in Nigeria affects the leadership role of women because Nigerian culture does not easily embrace the concept of women having leadership positions in the society. Men are perceived as heads of the family even where, as is the case these days, women are the bread winners. Nigerian culture in one respondent's view has grossly hampered the development of women. Less importance is attached to the birth and development of female children especially in the respondent's community. Ignorance and lack of extensive exposure has limited the potential of women leaders in Nigeria. "Women need more education, more exposure and more development to boost their self-esteem".

In as much as there is persistence to have more women in leadership, one respondent doubted that the Nigerian culture fully believes, and accepts what they profess. In Nigeria, the national culture is at least on the surface supportive of women in leadership positions, and at the family level, it varies. There is the assumption that a woman in leadership ceases to be womanly. For instance, "she loses all sense of femininity and womanliness, and so she is perceived as not fit for marriage. This trend in the group has seen a high number of professional women being unmarried”. Nigeria is a highly filial culture, and this results in added pressure on the professional woman for marriage and children from the family circle.

Finally, when asked what role the national and family culture has played on the leadership styles of women in Nigeria, many of the respondents stated that in education and knowledge, women needed to travel far and wide, to meet other women in leadership positions—especially those in the highest positions of leadership. "An educated woman makes a whole lot of difference as a mother, a mentor, a leader and a counselor".

\section{Descriptive summary2: Cultural values when exercising power}

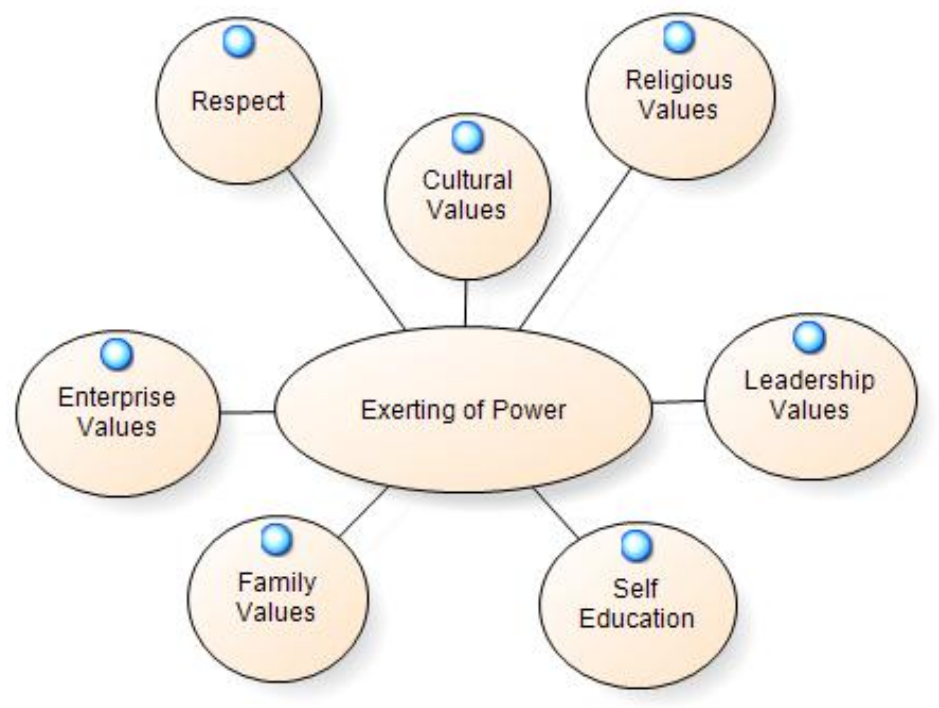

Figure 2. Cultural values when exerting power. 
When asked if respondents considered their cultural values when exerting power within the organization, the following were some of the patterns that emerged. Some of the participants responded by saying "yes" especially when addressing older generation of Nigerians whether at work, at home, or in social circles because of the Nigerian culture which gives more value and respect to older generation. One participant responded that as a leader, "they have to defer to those who are in higher positions regardless of their cultural values, respect other's opinions, listen to the wishes and aspirations of subordinates, and carry everyone along particularly the men-folk who may not believe in the abilities of a female leader". Some responded that generally, one huge problem is that men feel that women in positions of power are trying to measure up to them.

Several of the respondents answered that "No", they do not consider their cultural values when exercising power within the organization especially in a target driven one. They need to drive their subordinates regardless of their gender. One respondent answered that within the organization, Nigerian culture gives utmost regard to those who are older. "Good as it sounds; it creates obstacles in the workplace, when there is a need to delegate tasks, address, or discipline an older member of staff". Another participant responded that they did not consider their cultural values. "As a Nigerian woman, it comes naturally, though it could sometimes hinder the fast flow and regulations of a business".

One participant responded that they do not consider their cultural values in exercising their leadership because it does not add to their organizational growth. This participant further went on to say that leaders who want growth in their organizations had play by the rules and cultures present within their organization and not so much of the national or family cultures of Nigeria. They do need to be firm in their decision-making which they believe is the way forward. "Work place rules are sacrosanct. The office is not a village market square but a cooperate organization from which investors expect return on investment but that they do treat elders with respect”.

\section{Descriptive summary 3: Role of societal culture on leadership}

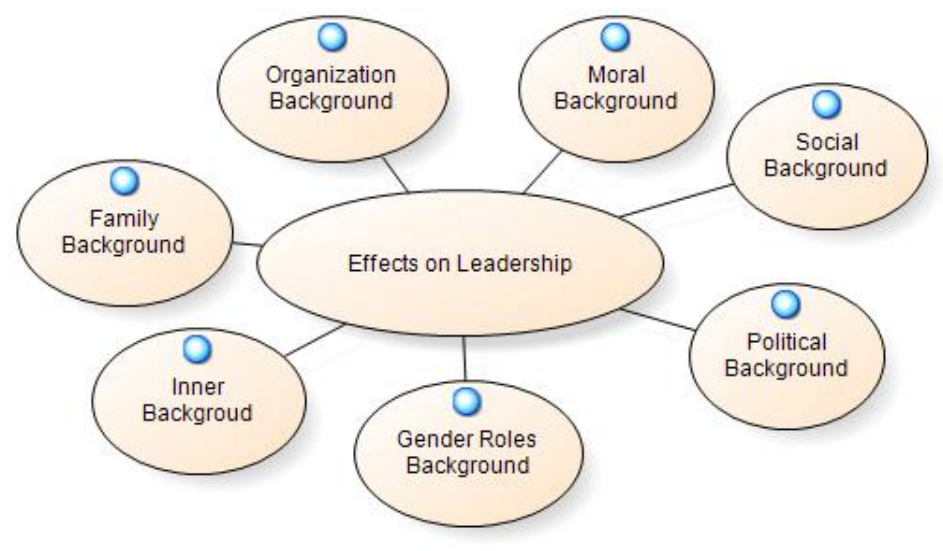

Figure 3. Role of societal culture on leadership.

Overall, many respondents answered positively on this question, in that their supportive family background, learned family values, moral support, boosted their self-esteem, and contributed immensely to their current leadership positions. "Societal culture has assisted many women in positions of power to learn to be good leaders" one respondent answered. They believed that one should earn one's position in society whether in the family, socially, or in the organization. Some respondents also believed that "one has to be a 
good follower before they can be a good leader”. Society expects women to be less corrupt and to maintain high moral standards in a largely corrupt society. Initially, one respondent was more considerate about cultural issues such as considering the manner they spoke to elders. However, the reality of the work environment is that the workplace culture dictates their leadership style.

One respondent answered that their strong determination in giving out the best of their leadership position to their employer does not allow societal, national culture or family background to affect the leadership style and view of power of one respondent. This respondent believed that their leadership style was impacted by their upbringing. One, in which family or national backgrounds did not affect their chosen leadership style. Nigeria is a country where respect for elders is very important. "There is the need to say 'Sir' or 'Ma' to older subordinates, and people in the society".

Culture and family background enhances the view of power, and on the leadership styles of one participant. One participant believed that "one should not let power go into one's head", but rather, use it to influence the quality, and nature they possess in others opinion to "be a good role model”. On the negative side, culture has affected the leadership styles of some participants tremendously because one should always keep the family background, Nigerian culture, one's peers and societal views of how a woman should behave in mind before dictating or delegating tasks in the business environment. "As much as women are crossing the cultural or societal barriers, it is still believed in some quarters that some positions cannot be held by women". Therefore, the role of national and family culture has both its positive and negative aspects in influencing the leadership styles of women, in Nigeria.

\section{Conclusion}

The 21st century has been met with increases in integrating cultures and economies on a faster pace (Suk-Hing Chan, 2005). There is a demand in the global economy for national cultures to adjust and adapt to global market trends. From this wide-scale of multi-national business practices in cross-cultural environments, both national and organizational leaders can step outside of their country's norms as new national cultures and leadership practices emerge. As the world integrates businesses and cultures, many organizational leaders are crossed between their cultural beliefs, norms, practices, and leadership approaches in the ways in which they understand cultural influences on leadership (Hanges et al., 2000). The findings from the responses of this section of the research varied on participants' demographics and leadership experiences with both the national and family cultures present in Nigeria.

\section{Summary}

Some factors that have contributed to the need for organizational leaders to adapt, and adjust to other national cultures are the globalization of the workforce, the expansion of international companies, and exposure of many national organizations to increased business competition. The increased competition has forced organizational leaders to engage in understanding of the cultural limitations of organizations and their leadership practices. In addition, cross-cultural leadership researchers in the 21st century are cognizant of the fact that culture is a condition, and a boundary to previous leadership theories and practices (Hanges et al., 2000).

The purpose of this section of the research was to investigate Nigerian women in leadership positions and the relationship of both national and family cultures as they relate to their leadership practices. This 
section $^{3}$ of the research study provides the descriptive analysis on power and organizational leadership as they relate to both National and Family Cultures and to understand the effects of both national and family culture on power relations within the participant's respective places of business or organizations. The questions for this section were asked to understand the perspectives of research participants as they interpret their perceptions and the ways in which both national and family culture affected their leadership characteristics.

A phenomenological qualitative research study explored the culture and leadershipin a cross-cultural environment, examining both national and family cultures as the basis for cross-cultural leadership, and utilizing Gerte Hofstede's five cultural dimensions of culture: power distance, individualism versus collectivism, masculinity versus femininity, and long-term versus short-term orientation were used analysis for this section of the research on culture and leadership. The research was conducted amongst a group of 50 women, ages 35 to 50 years of age who were in leadership positions in an organization working to increase the number of women in management and leadership positions in Nigeria. An open-ended survey questionnaire was appropriate for the proposed research study because it allowed participants to describe their day-to-day lived experiences. The researcher gathered insights into the lived experiences of a like-minded sample of respondents from the research population as they described their cross-cultural leadership experiences.

\section{References}

Alapo, R. (2011). The role of culture on the leadership styles of women in Nigeria: A phenomenological study. School of Advanced Studies, University of Phoenix, Arizona.

Ardichvili, A., \& Kuchinke, K. P. (2002). Leadership styles and cultural values among managers and subordinates: A comparative study of four countries of the former Soviet Union, Germany, and the US. Human Resource DevelopmentInternational, 5(1), 99-117.

Bunge, M. (2000). Ten modes of individualism-none of which works-and their alternatives. Philosophy of the Social Sciences, 30(3), 384-406.

Dastmalchian, A., Javidan, M., \& Alam, K. (2001). Effective leadership and culture in Iran: An empirical study. Applied Psychology: An International Review, 50(4), 532-558.

David, J. P. (2007). Cross-cultural perspectives on knowledge management. Libraries Unlimited. Westport, CT.

Ejiofor, P. N. O. (1987). Management in Nigeria: Theories and issues. Onitsha, Nigeria: Longman.

Hanges, P. J., Lord, R. G., \& Dickson, M. W. (2000). An information-processing perspective on leadership and culture: A case for connectionist architecture. Applied Psychology—An International Review, 49(1), 133-161.

Hofstede, G. (1980). Culture's consequence: International differences in work-related values. Beverly Hills, CA: Sage.

Hofstede, G. (1991). Culture and organizations. New York: Harper Collins.

Hofstede, G. (2001). Culture's consequences: Comparing values, behaviors, institutions and organizations across nations. Thousand Oaks, CA: Sage.

Hoppe, M. H. (1990). A comparative study of country elites: International differences in work-related values and learning and their implications for management training and development. Journal of International Business Studies, 23(3), 590.

Hunt, G. I., Osborn, N. R., \& Shermerhorn, R. J. (1991). Organizational behavior. New York: John Wiley \& Sons.

Kluckhohn, C. (1951). The study of culture: The policy sciences. Stanford, C.A.: Stanford University Press.

Lee, I. (1992). An analysis of conflict management techniques used by Korean employees and American employees working in public and private organizations in United States (Unpublished doctoral dissertation, Cornell University).

Lee, W. L. (2001). Leadership. New York: Macmillan Reference USA.

Ling, W., Chia, R. C., \& Fang, L. (2000). Chinese implicit leadership theory. The Journal of Social Psychology, 140(6), $729-739$.

Markus, H. R., \& Kitayama, S. (1991). Culture and the self: Implications for cognition, emotion, and Motivation. Psychological Review, 98, 224-253.

${ }^{3}$ These results are the descriptive analysis which have been revised and were based on the section on Culture and Leadership in the 21st Century. A dissertation research conducted by Alapo, R. (2011) titled: The Role of Culture on the Leadership Styles of Women in Nigeria: A Phenomenological Study. 
Mom-Chhing, C. (2009). Towards understanding Cambodian American leadership culture: A grounded theory. University of Phoenix, Arizona.

Neumann, W. L. (2003). Social research method: Qualitative and quantitative approaches (4th ed.). Boston: Pearson Education.

Newman, K., \& Nollen, S. (1996). Culture and congruence: The fit between management practices and national culture. Journal of International Business Studies, 27(44), 753-779.

Okpara, J. (1996). An examination of the relationship of motivation needs, cultural factors, and job satisfaction among managers in selected business enterprises in Nigeria (Unpublished doctoral dissertation, New York University, New York).

Okpara, J. O. (2007). The effect of culture on job satisfaction and organizational commitment: A study of information system managers in Nigeria. Journal of African Business, 8(1), 113-130.

Randolph, W. A., \& Sashkin, M. (2002). Can organizational empowerment work in multinational settings? Academy of Management Perspective, 16(1), 102-115.

Rodriguez, C. (1996). International management: A cultural approach. Mason, OH: South-Western.

Rosenhauer, S. (2007). Cross cultural business communication: Intercultural competence as a universal inter culture. Munich: GRIN Verlag.

Stata, R. (1992). What is individualism? Speech at the MIT Radicals for Capitalism, Cambridge, MA.

Suk-Hing Chan, D. (2005). Relationship between generation-responsive leadership behaviors and job satisfaction of Generation $X$ and $Y$ professionals. University of Phoenix, Arizona.

Triandis, H. C. (1989). The self and social behavior in differing cultural context. Psychological Review, 96, 506-520.

Unger, A., Papastamatelou, J., Gassemi, K., \& Lu, A. (2014). The relationship between the Zimbardo Time Perspective Inventory (ZTPI) and the Hofstede-Dimensions: Preliminary empirical evidence from Germany, Morocco, and China. Open Journal of Social Sciences, 2, 100-105.

Zagorsek, H. (2004). Universality versus cultural contingency of leadership: A comparative study of leadership practices in six countries. University of Ljubljana.

Zhang, X. (1994). A comparative study of the perspective of managerial role behavior: Cultural-common and cultural-specific perspectives (Unpublished doctoral dissertation, University of Missouri, Columbia). 